\title{
Immune and Autoimmune Enteropathies
}

\author{
Philip M. Sherman ${ }^{a}$ Ernest Cutz ${ }^{a}$ Olivier Goulet ${ }^{b}$ \\ ${ }^{a}$ Hospital for Sick Children, University of Toronto, Toronto, Ont., Canada; ${ }^{b}$ Groupe Hospitalier \\ Necker-Enfant Malade, Paris, France
}

\section{Key Words}

Diarrhea, children and infants $\cdot$ Enteropathy, immune and autoimmune $\cdot$ IPEX syndrome $\cdot$ Autoimmunity

\begin{abstract}
Autoimmune enteropathy characteristically presents in infancy with protracted diarrhea. Underlying disorders of immune function, including regulatory $T$ cells, must be excluded. Treatment options include nutritional rehabilitation, immune suppression, and, in select cases, bone marrow transplant.
\end{abstract}

Copyright $\odot 2006$ Nestec Ltd., Vevey/S. Karger AG, Basel

\section{Introduction}

Autoimmune enteropathy and enteropathies due to primary immune deficiencies are relatively uncommon causes of protracted diarrhea during infancy. When confronted with an infant or young child with chronic unexplained diarrhea, the differential diagnosis is quite extensive [1] and distinct from the considerations in assessing an adult with the same clinical symptoms [2, 3]. In most parts of the world, infectious and post-infectious enteropathies remain the most common causes of protracted diarrhea [4]. Some investigators contend that allergic enteropathies also are common in young children, even in the absence of other atopic symptoms or a family history of an allergic predisposition. Much more commonly, milk and soy protein-induced allergic colitis develops in newborns and infants, including those receiving breast milk as their sole source of nutrients. In an older child who has received gluten in the diet, it is important to consider celiac disease as the underlying cause of symptoms since it is increasingly apparent that gluten-sensitive enteropathy has protean manifestations and is a life-long condition that can be treated effectively and safely with appropriate dietary adjustments [5].

One helpful way to consider alternative etiologies is to differentiate those causes of chronic diarrhea in which there is a relatively intact villus-crypt unit from those with abnormal villus-crypt architecture (i.e. an enteropathy). In the former scenario, conditions such as congenital disorders of ion transport and secretory diarrhea, due to bacterial enterotoxins and hormone-secreting tumors, need to be considered [1]. By contrast, an enteropathy with a reduction in villus height should bring to mind a completely different set of diagnostic considerations. After infectious and allergic etiologies have been excluded, chronic high volume diarrhea beginning in the first few days of life should raise microvillus inclusion disease for diagnostic consideration [6]. This latter condition also is referred to as familial microvillous atrophy [7] or Davidson's syndrome.

\section{KARGER \\ Fax +41613061234 E-Mail karger@karger.ch} www.karger.com (c) 2006 Nestec Ltd., Vevey/S. Karger AG, Basel 0517-8606/06/0641-0007\$23.50/0

www.karger.com/ane
Philip M. Sherman, MD, FRCPC

Gastroenterology and Nutrition, Room 8409

Hospital for Sick Children, 555 University Avenue

Toronto, Ont. M5G 1 X8 (Canada)

Tel. +1 416813 7734, Fax +1 416813 6531, E-Mail philip.sherman@sickkids.ca 
With slightly later onset of chronic diarrhea, a condition that can present much like autoimmune enteropathy is tufting enteropathy [8], which also is referred to as intestinal epithelial dysplasia [9]. Interestingly, many of the infants reported from both Europe and North America with this enteropathy are from families originally from North Africa, Turkey and, especially, the island of Malta. As a result, tufting enteropathy certainly should be considered seriously in infants of these backgrounds.

\section{Clinical Presentation}

Children with autoimmune enteropathy typically present after the neonatal period, but within the first year of life. A history of maternal polyhydramnios during the pregnancy and/or a family history of other affected children should direct a search for other causes of protracted diarrhea of neonatal onset including, for example, congenital chloride-losing enteropathy [1].

Most cases of autoimmune enteropathy begin with chronic, watery and unremitting diarrhea between 2 and 4 months of age after an uneventful pregnancy and neonatal period. However, the later onset of symptoms is well described, including isolated case reports of initial manifestations of diarrheal disease during adolescence [10] and the adult years [11]. These older-onset patients typically carry the diagnosis of refractory sprue, until an analysis for the presence of anti-enterocyte antibodies is carried out. It remains to be established whether the later onset of symptoms is due to the same molecular basis of disease as for those with the development of diarrhea during the first year of life.

Although such autoimmune conditions primarily manifest as enteropathies, the colon often is involved as well. Signs and symptoms of colitis (for example: urgency, tenesmus, hematochezia and mucus in the stools) accompanying protracted diarrhea that is unresponsive to a trial of elemental feeding - particularly in association with impaired growth and undernutrition - should raise the suspicion of an autoimmune enteropathy.

The presence of other autoimmune conditions also raises the risk of autoimmune enteropathy. Initial cases of autoimmune enteropathy described in the scientific literature were associated with type-1 diabetes mellitus, autoimmune thyroiditis, autoimmune hemolytic anemia and skin conditions that likely had an autoimmune basis. Many of the affected cases reported also were associated with tubulonephropathy.

\section{Histopathologic Findings}

Small bowel biopsies in infants and children with protracted diarrhea are extremely helpful. Results of morphology and immunohistochemistry are not only helpful in establishing a specific diagnosis, but frequently also can exclude other conditions when such evaluations are not definitive [12].

In cases of autoimmune enteropathy, light microscopy findings (fig. 1a) often resemble many of the features associated with gluten-sensitive enteropathy even when affected children have not been challenged with gluten. Examinations of sections stained with hematoxylin and eosin often reveal total villus atrophy and crypt hyperplasia. In addition, there often is marked immune cell infiltration including activated $T$ cells [13], into the lamina propria of the intestinal mucosa. There also can be morphological evidence of intraepithelial lymphocytes, but not to the same degree as that observed in children with total villus atrophy caused by celiac disease [14]. Immunohistochemistry, with relevant antibodies as markers, provides evidence of a marked infiltration of $\mathrm{CD} 3+\mathrm{T}$ cells into the lamina propria (fig. 1b). Recent findings indicate that the cytokine interleukin-21 may mediate T-cell activation, impaired survival of the cells and ultimately predispose the affected host to autoimmune diseases [15].

Colonic biopsies also show evidence of immune cells infiltrating the lamina propria in children with autoimmune enteropathy. This finding is in contrast to other causes of protracted diarrhea in infants in whom evidence of immune activation other than in the small bowel is not observed [14].

\section{Autoantibodies}

A hallmark of autoimmune enteropathy is the presence in serum of immunoglobulin $\mathrm{G}$ antibodies, usually circulating in low titer, which bind to apical aspect of enterocytes (fig. 2). In one report on 25 children with unexplained chronic diarrhea, anti-enterocyte antibodies were detected in 14(56\%) subjects, compared with positive test results in $3(5 \%)$ of 53 patients with chronic inflammatory bowel diseases, 0 of 10 with celiac disease and none of the 50 children with other conditions unrelated to the gastrointestinal tract [16]. The antibody is not specific to an epitope on human enterocytes, because the autoantibodies also bind to small bowel epithelial cells in intestinal sections obtained from rats, mice and guinea pigs. The antigen also is detected in renal epithelium. 
Fig. 1. a Biopsy of the small bowel mucosa obtained from a child with protracted diarrhea. The biopsy shows total villus atrophy with crypt hyperplasia and infiltration of the lamina propria by a mixed chronic inflammatory cell infiltrate. HE. Approximate original magnification $\times 20$. b Immunohistochemistry with anti-CD3 antibody demonstrates infiltration of the lamina propria by numerous CD3+ T cells. Approximate original magnification $\times 20$.
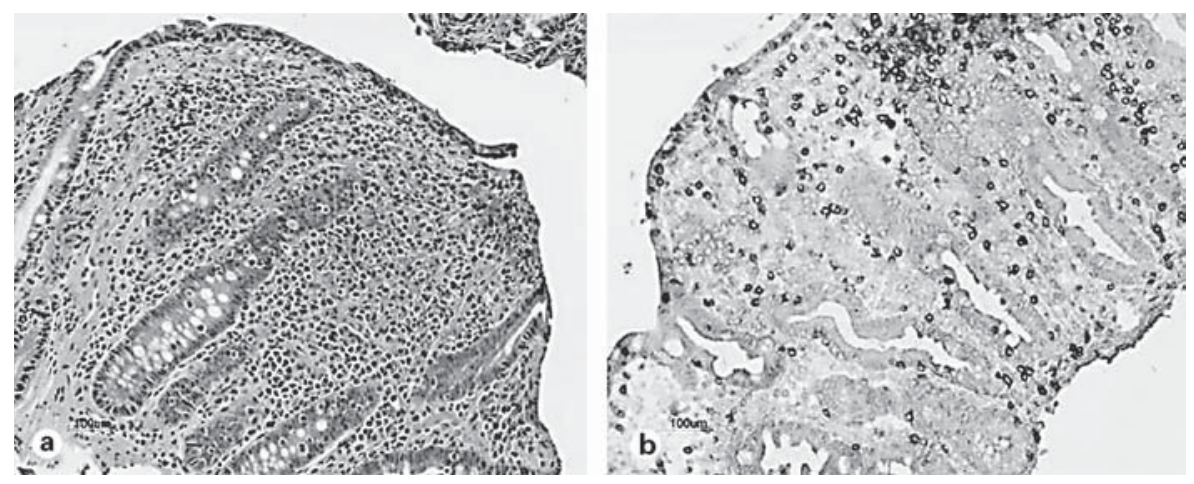

Fig. 2. Indirect immune fluorescence demonstrates the presence of anti-enterocyte antibodies in the serum of a child with autoimmune enteropathy. Fluorescent staining outlines the apical surface of enterocytes along the villus-crypt unit.

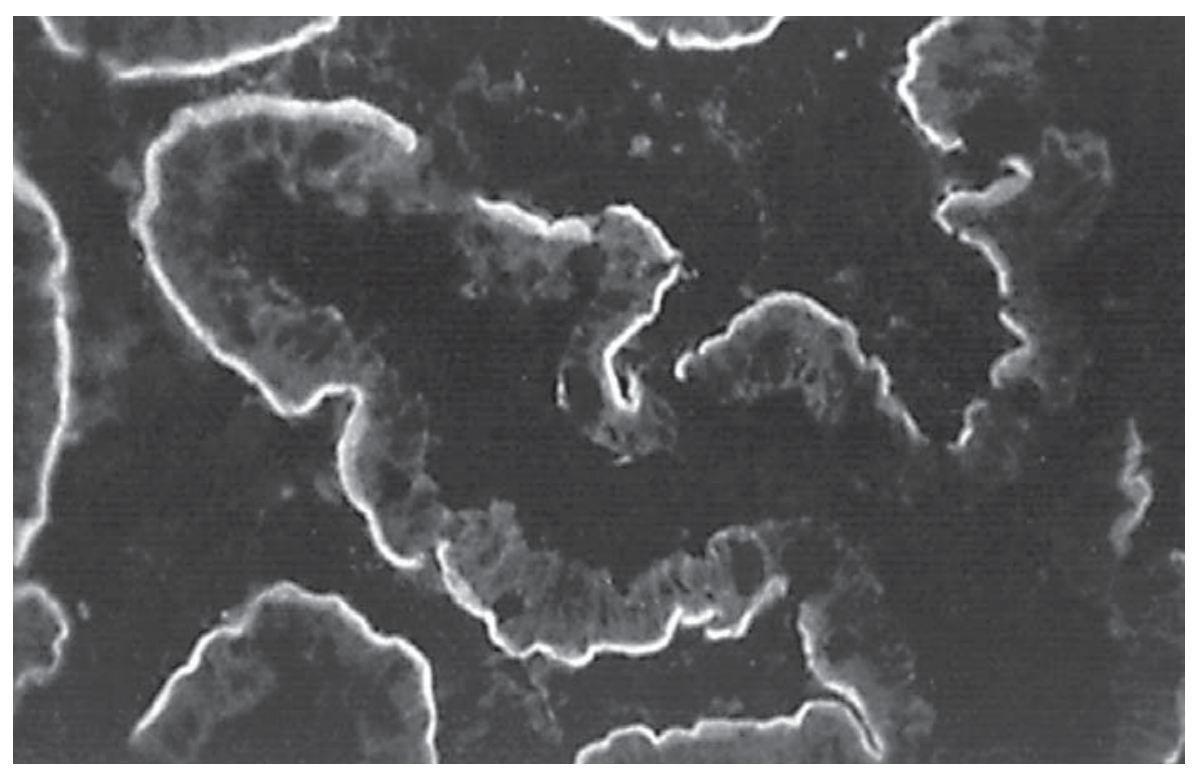

Western blots show that autoantigens are either 55 [17] or $75 \mathrm{kDa}[18,19]$. The $75-\mathrm{kDa}$ autoantigen is expressed in the small bowel, large intestine, pancreas and kidney [20]. With therapy (considered below), titers of circulating anti-enterocyte antibodies are reduced, or disappear progressively and completely with clinical improvement. Therefore, systemic autoantibody levels can be monitored as an objective measure of responsiveness to clinical interventions [17].

Even though molecular targets for anti-enterocyte antibodies have been described, other investigators observed that the test may not be sufficiently specific. For instance, Martin-Villa et al. [21] noted the presence of such autoantibodies in the systemic circulation of subjects without villous atrophy and with no history of diarrhea. Thus as with any other screening tests, these antienterocyte antibody assessments must be placed in appropriate clinicopathological contexts.
A few case reports describe an autoimmune enteropathy in which systemic autoantibodies are directed against the goblet cell lineage rather than apical regions of enterocytes [22]. Intestinal biopsies in these cases show a lack of goblet, Paneth and enteroendocrine cells [23]. This may reflect a deficiency in the transcription factor, Math1 [24]. The clinical and pathological findings are otherwise similar to those in other cases of autoimmune enteropathy. This finding supports the view that infiltrating $\mathrm{T}$ cells, rather than the systemic autoantibodies, are involved in mediating the disease's pathobiology. Thus, autoantibodies likely provide markers of an underlying condition which develops as a result of mucosal inflammation and injury, rather than being specifically involved in disease pathogenesis $[13,14]$. 


\section{Primary Immune Deficiency Disorders}

A variety of immune disorders of genetic origin can cause intestinal injury resulting in enteropathy, malabsorption of nutrients, and protracted diarrhea [25]. For instance, chronic granulomatous disease and glycogen storage disease type $1 \mathrm{~b}$ both have been associated with mucosal inflammation along the length of the gastrointestinal tract, with clinical, radiological, and endoscopic features that can mimic those observed in chronic inflammatory bowel diseases. Eosinophilic gastroenteritis also should be considered in the differential diagnosis.

It is now clear that there are multiple causes of what previously had been lumped together in the single entity referred to as autoimmune enteropathy. For example, primary T-cell immune deficiencies are reported to present with features of autoimmune disease. For instance, Arniaz-Villena et al. [26] reported a kindred in which there was a congenital defect in the expression of the CD3- $\gamma$ subunit of the T-cell receptor complex. The affected proband presented with protracted diarrhea in association with autoantibodies against gut epithelial cells, smooth muscle and mitochondria, as well as autoimmune hemolytic anemia and a selective $\operatorname{IgG} 2$ subclass deficiency.

Two children with Schimke immuno-osseous dysplasia and abnormal T-cell immune function were described in the literature $[27,28]$. Both children presented with chronic diarrhea and signs and symptoms consistent with autoimmune enteropathy. However, autoantibodies were not present and atypical Mycobacteria were identified in the small bowel mucosa in one child [28]. This observation serves to reinforce and highlight the importance of excluding chronic infection and underlying immunodeficiency state in a child with unexplained protracted diarrhea.

\section{IPEX Syndrome}

Immune dysregulation, polyendocrinopathy, enteropathy, and X-linked (IPEX) syndrome is the most specific and well-documented underlying cause of autoimmune enteropathy. The disease is caused by mutations in the Foxp3 gene carried in the peri-centromeric region of the X chromosome: Xp11.23-Xp13.3 [29, 30]. Foxp3 (also variously referred to as $J M 2$ and scurfin) is a transcription factor that is critical for control of the normal development of regulatory $\mathrm{T}$ cells $[31,32]$. When mutated, the normal control of CD25+ T cells is lost $[33,34]$ and there is an inappropriate activation and dissemination of activated immune cells to multiple organs, including the intestinal tract (fig. 3).

Several FoxP3 gene mutations have been reported that cause human disease. There is probably a genotype-phenotype relationship explaining differences observed in terms of clinical expression, disease severity, number of extra-digestive autoimmune manifestations, and prognoses [35]. As a result, autoimmune enteropathy can be subdivided into those cases due to IPEX, affected males without evidence of a mutation in the FoxP3 gene, and affected girls [36].

Male infants with IPEX syndrome present in infancy with type-1 diabetes mellitus, autoimmune thyroiditis, autoimmune hemolytic anemia (positive direct Coomb's test) and a variety of skin lesions, including eczema, an ichthyosiform dermatitis, psoriatic dermatitis and alopecia universalis [37]. Protracted high-volume diarrhea, due to an autoimmune enteropathy, is generally a prominent presenting feature. These children also may present with atopic features, including food allergies, peripheral eosinophilia and raised levels of immunoglobulin E [38]. Cases of autoimmune enteropathy occurring in boys (especially if there are multiply affected siblings in the same family) with evidence of autoantibodies directed against other organs and evidence of systemic autoimmune diseases, which have been published previously in the medical literature, should be considered as possible cases of IPEX syndrome.

\section{Therapeutic Considerations}

The initial management of infants with chronic diarrhea in whom autoimmune enteropathy is a diagnostic consideration is precisely the same as that for all other affected individuals. The initial focus should target the maintenance of intravascular volume and nutritional rehabilitation, which generally requires either continuous elemental, enteral venous infusion or total parental alimentation. Children often are left dehydrated and undernourished during extensive in-hospital diagnostic evaluations. This approach is deplorable: fluid and nourishment are among the first priorities [39]. Only after these are provided should health care providers pause to consider the long list of potential considerations in the differential diagnosis.

Autoimmune enteropathy generally responds well to potent suppression of the hosts' immune system. Highdose systemic corticosteroids frequently will reduce mu- 
Fig. 3. Histology of the small bowel in a child with IPEX syndrome shows evidence of total villous atrophy and marked inflammation of the lamina propria with a chronic inflammatory cell infiltrate.

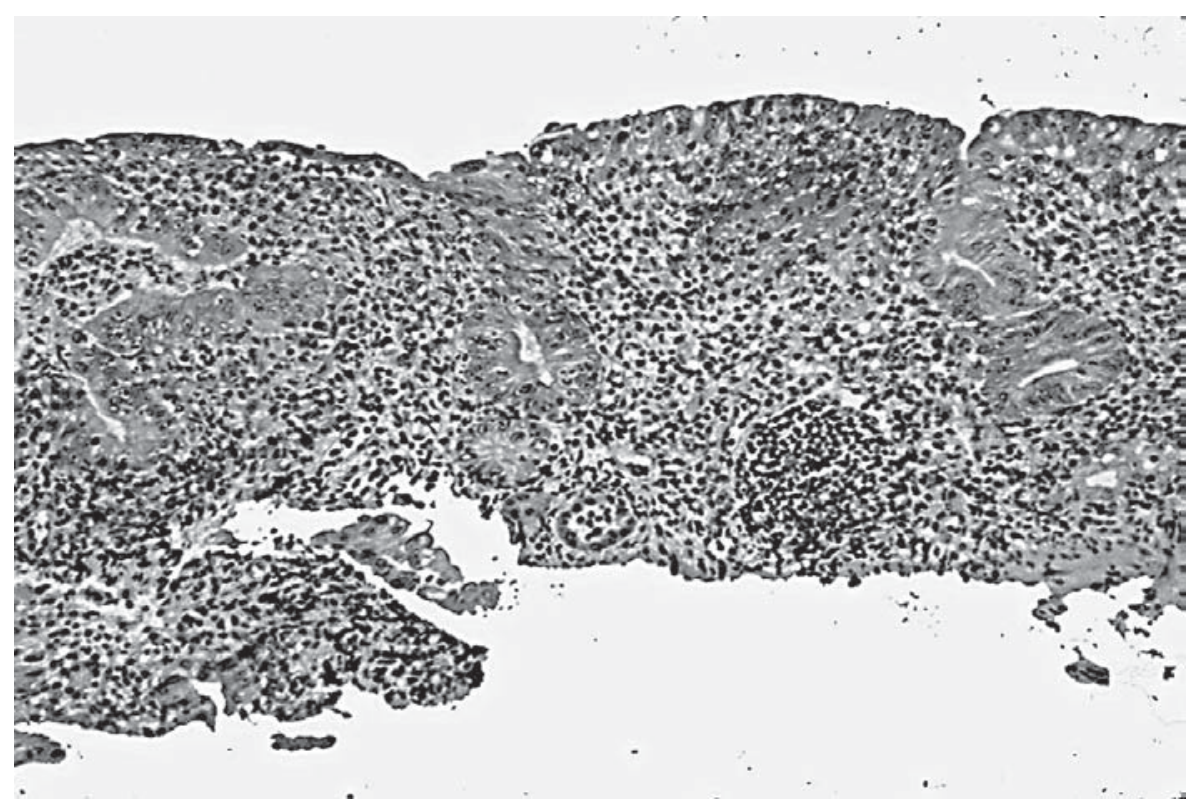

cosal inflammation, lower stool output and permit increased enteral delivery of calories. Autoantibody titers are reduced in parallel with clinical responses to medical therapies. However, steroid dependence (that is, recurrence of symptoms following a tapering of the corticosteroid dose) is the norm. Steroid resistance (i.e. absence of an apparent response to therapy) is also common. As a result, a number of other potent immune-suppressive agents have been employed. Case reports indicate apparent clinical benefits of a variety of therapies such as cyclosporine [40, 41], tacrolimus [42], sirolimus [43], mycophenolate mofetil [44], cyclophosphamide [45] and biologic agents such as the chimeric monoclonal antibody against tumor necrosis factor- $\alpha$, infliximab [46].

Most affected children respond to potent suppression of the immune system and, ultimately, tolerate advancing enteral feedings and concurrent reductions in parenteral nutritional supports. As a result, autoimmune enteropathy should not be considered as an indication for undertaking small bowel transplant. This clinical prognosis stands in stark contrast to most cases of microvillus inclusion disease where there is no response to potent immune suppression and the outcome is guarded in the absence of intestinal transplantation, at least as a therapeutic option $[1,6,12]$.

Whether these children may benefit from alternate therapeutic strategies, such as bone marrow transplantation, is not known. Reported benefits of transplanting bone marrow-derived cells in children with IPEX syn- drome [47] suggest that this approach is worth further consideration in severely affected cases with a limited or partial response to potent suppression of the immune system. Positive responses of children with IPEX syndrome to allogeneic bone marrow transplantation also emphasize the critical importance of establishing the correct underlying diagnosis of protracted diarrhea in infants and young children. Lumping affected cases together as socalled intractable diarrhea of infancy is unhelpful and may impair consideration of appropriate therapeutic options.

Careful consideration of the precise etiology of protracted diarrhea is also essential in considering genetic counseling of families with affected children. Most cases of autoimmune enteropathy appear to be sporadic without other affected family members or evidence of parental consanguinity. On the other hand, IPEX syndrome is an X-linked condition. This raises other issues related to risk in affected families that are beyond this review.

\section{Conclusions}

Autoimmune enteropathy is a term used to describe a relatively uncommon cause of protracted diarrhea in infants. This is a severe inflammatory condition, which generally is responsive to immune suppression therapy. It is quite likely that autoimmune enteropathies encompass a number of etiologies that require better definitions 
to enable future targeting of appropriate therapies and genetic counseling. Further research should define underlying immune disorders and pathophysiological processes that result in the disease's clinical manifestations. Appropriate relevant animal models likely will prove to be exceptionally helpful in the disease processes' delineation.

To identify genetic mutations accounting for autoimmune enteropathy, fibroblasts from a skin biopsy should be immortalized for cell culture. Similarly, messenger RNA should be isolated from intestinal biopsies for use in whole genome scanning, which is already technologi- cally feasible and economically viable as a powerful research tool [48]. An international collaborative research effort also will improve the current understanding of the molecular basis of chronic immune-mediated enteropathies.

\section{Acknowledgments}

P.M.S. is the recipient of a Canada Research Chair in Gastrointestinal Disease. Work in the authors' laboratories is funded by operating grants from the Canadian Institutes of Health Research.

\section{References}

1 Sherman PM, Mitchell DJ, Cutz E: Neonatal enteropathies: defining the causes of protracted diarrhea of infancy. J Pediatr Gastroenterol Nutr 2004;38:16-26.

2 Camilleri M: Chronic diarrhea: a review on pathophysiology and management for the clinical gastroenterologist. Clin Gastroenterol Hepatol 2004;2:198-206.

-3 Schiller LR: Chronic diarrhea. Gastroenterology 2004;127:287-293.

4 Bhutta ZA, Ghishan F, Lindley K, Memon IA, Mittal S, Rhoads JM: Persistent and chronic diarrhea and malabsorption: Working Group report of the second World Congress of Pediatric Gastroenterology, Hepatology, and Nutrition. J Pediatr Gastroenterol Nutr 2004; 39(suppl 2):S711-S716.

-5 Hill ID, Dirks MH, Liptak GS, et al: Guideline for the diagnosis and treatment of celiac disease in children: recommendations of the North American Society for Pediatric Gastroenterology, Hepatology and Nutrition. J Pediatr Gastroenterol Nutr 2005;40:1-19.

-6 Cutz E, Rhoads JM, Drumm B, et al: Microvillus inclusion disease: an inherited defect of brush-border assembly and differentiation. $\mathrm{N}$ Engl J Med 1989;320:646-651.

7 Phillips AD, Schmitz J: Familial microvillous atrophy: a clinicopathological survey of 23 cases. J Pediatr Gastroenterol Nutr 1992;14: 380-396.

8 Reifen RM, Cutz E, Griffiths AM, et al: Tufting enteropathy: a newly recognized clinicopathological entity associated with refractory diarrhea in infants. J Pediatr Gastroenterol Nutr 1994;18:379-385.

-9 Patey N, Scoazec JY, Cuenod-Jabri B, et al: Distribution of cell adhesion molecules in infants with intestinal epithelial dysplasia (tufting enteropathy). Gastroenterology 1997;113: 833-843.
10 Pirisi-Hauck NC, Foss H-D, Baier J, Kurunczi $\mathrm{S}$ : Simultaneous occurrence of autoimmune enteropathy and recurrent deep vein thrombosis. J Pediatr Gastroenterol Nutr 2000;30:324329.

11 Carroccio A, Volta U, Di Prima L, et al: Autoimmune enteropathy and colitis in an adult patient. Dig Dis Sci 2003;48:1600-1606.

12 Cutz E, Sherman PM, Davidson GP: Enteropathies associated with protracted diarrhea of infancy: clinicopathological features, cellular and molecular mechanisms. Pediatr Pathol Lab Med 1997;17:335-368.

13 Murch SH, Fertleman CR, Rodrigues C, et al: Autoimmune enteropathy with distinct mucosal features in T-cell activation deficiency: the contribution of $\mathrm{T}$ cells to the mucosal lesion. J Pediatr Gastroenterol Nutr 1999;28:393-399.

14 Cuenod B, Brousse N, Goulet O, et al: Classification of intractable diarrhea of infancy using clinical and immunohistological criteria. Gastroenterology 1990;99:1037-1043.

15 King C, Lic A, Koelsch K, Sarvetnick N: Homeostatic expansion of $\mathrm{T}$ cells during immune insufficiency generates autoimmunity. Cell 2004; 117:265-277.

16 Mirakian R, Richardson A, Milla PJ, et al: Protracted diarrhoea of infancy: evidence in support of an autoimmune variant. Br Med J (Clin Res Ed) 1986;293:1132-1136.

17 Colletti RB, Guillot AP, Rosen S, et al: Autoimmune enteropathy and nephropathy with circulating anti-epithelial cell antibodies. J Pediatr 1991;118:858-864.

18 Kobayashi I, Imamura K, Yamada M, et al. A $75-\mathrm{kD}$ autoantigen recognized by sera from patients with X-linked autoimmune enteropathy associated with nephropathy. Clin Exp Immunol 1998;111:527-531.

19 Kobayashi I, Imamura K, Kubota M, et al: Identification of an autoimmune enteropathyrelated 75-kilodalton antigen. Gastroenterology 1999;117:823-830.
20 Ishikawa S, Kobayashi I, Hamada J-I, et al: Interaction of MCC2, a novel homologue of MCC tumor suppressor, with PDZ-domain protein AIE-75. Gene 2001;267:101-110.

-21 Martin-Villa JM, Regueiro JR, De Juan D, et al: T-lymphocyte dysfunctions occurring together with apical gut epithelial cell autoantibodies. Gastroenterology 1991;101:390-397.

22 Moore L, Xu X, Davidson G, et al: Autoimmune enteropathy with anti-goblet cell antibodies. Hum Pathol 1995;26:1162-1168.

23 Shaoul R, Hong D, Okada Y, Cutz E, Marcon M: Lineage development in a patient without goblet, Paneth and enteroendocrine cells, a clue for intestinal epithelial differentiation. Pediatr Res 2005, in press.

24 Yang Q, Berminham A, Finegold MJ, et al: Requirement of Math1 for secretory cell lineage commitment in the mouse intestine. Science 2001;294:2155-2158

25 Goulet O, Seidman E: Gastrointestinal manifestations of immunodeficiency. 1. Primary immunodeficiency diseases; in Walker W, Goulet O, Kleinman R, Sherman P, Shneider B, Sanderson I (eds): Pediatric Gastrointestinal Disease, ed 4. Philadelphia, B.C. Decker, 2004, pp 707-733.

-26 Arniaz-Villena A, Timon M, Corell A, et al: Primary immunodeficiency caused by mutations in the gene encoding the CD3-gamma subunit of the T-lymphocyte receptor. N Engl J Med 1992;327:529-533.

27 Kaitila I, Savilahti E, Ormala T: Autoimmune enteropathy in Schimke immunoosseous dysplasia. Am J Med Genet 1998;77:427-430.

28 Stormon M, Friedman J, King S, Cutz E, Furuya $\mathrm{KN}$ : An unusual case of diarrhea in Schimke immuno-osseous dysplasia. J Pediatr Gastroenterol Nutr 2002;35:369-371. 
-29 Bennett CL, Christie J, Ramsdell F, et al: The immune dysregulation, polyendocrinopathy, enteropathy, X-linked syndrome (IPEX) is caused by mutations of FOXP3. Nat Genet 2001;27:20-21.

-30 Ochs HD, Ziegler SF, Torgerson TR: FOXP3 acts as a rheostat of the immune response. Immunol Rev 2005;203:156-164.

-31 Hori S, Nomura T, Sakaguchi S: Control of regulatory $\mathrm{T}$ cell development by the transcription factor FOXP3. Science 2003;299:1057-1061.

$\checkmark 32$ Hori S, Sakaguchi S: Foxp3: a critical regulator of the development and function of regulatory T cells. Microbes Infect 2004;6:745-751.

$\checkmark 33$ Fontenot JD, Gavin MA, Rudensky AY: FOXP3 programs the development and function of CD4+CD25+ regulatory T cells. Nat Immunol 2003;4:330-336.

>34 Bakke AC, Purtzer MZ, Wildin RS: Prospective immunological profiling in a case of immune dysregulation, polyendocrinopathy, enteropathy, X-linked syndrome (IPEX). Clin Exp Immunol 2004; 137:373-378.

-35 Eisenbarth GS, Gottlieb PA: Autoimmune polyendocrine syndromes. N Engl J Med 2004; 350:2068-2079.
36 Ruemmele FM, Brousse N, Goulet O: Autoimmune enteropathy: molecular concepts. Curr Opin Gastroenterol 2004;20:587-591.

37 Nieves DS, Phipps RP, Pollock SJ, et al: Dermatologic and immunologic findings in the immune dysregulation, polyendocrinopathy, enteropathy, X-linked syndrome. Arch Dermato 2004; 140:466-472.

38 Patel DD: Escape from tolerance in the human $\mathrm{X}$-linked autoimmunity-allergic disregulation syndrome and the Scurfy mouse. J Clin Invest 2001;107:155-157.

39 Lo CW, Walker WA: Chronic protracted diarrhea of infancy: a nutritional disease. Pediatrics 1983;72:786-800.

40 Seidman EG, Lacaille F, Russo P, et al: Successful treatment of autoimmune enteropathy with cyclosporine. J Pediatr 1990;117:929-932.

41 Sanderson IR, Phillips AD, Spencer J, WalkerSmith JA: Response to autoimmune enteropathy to cyclosporin A therapy. Gut 1991;32: 1421-1425.

42 Bousvaros A, Leichtner AM, Book L, et al Treatment of pediatric autoimmune enteropathy with tacrolimus (FK506). Gastroenterology 1996;111:237-243.

43 Bindl L, Torgerson T, Perroni L, Youssef N, Ochs HD, Goulet O, Ruemmele FM: Successful use of the new immune-suppressor sirolimus in IPEX (immune dysregulation, polyendocrinopathy, enteropathy, X-linked syndrome). J Pediatr 2005, in press.
44 Quiroz-Tejeira RE, Ament ME, Vargas JH: Induction of remission in a child with autoimmune enteropathy using mycophenolate mofetil. J Pediatr Gastroenterol Nutr 2003;36: 482-485.

45 Oliva-Hemper MM, Loeb DM, Abraham SC, et al: Remission of severe autoimmune enteropathy after treatment with high-dose cyclophosphamide. J Pediatr Gastroenterol Nutr 2003;36:639-643.

46 Vanderhoof JA, Young RJ: Autoimmune enteropathy in a child: response to infliximab therapy. J Pediatr Gastroenterol Nutr 2002;34: 312-316.

47 Baud O, Goulet O, Canioni D, et al: Treatment of the immune dysregulation, polyendocrinopathy, enteropathy, X-linked sydrome (IPEX) by allogeneic bone marrow transplantation. $\mathrm{N}$ Engl J Med 2001;344:1758-1762.

48 Collins SM, McHugh K, Croitoru K, et al: The establishment of a national tissue bank for inflammatory bowel disease research in Canada. Can J Gastroenterol 2003;17:107-109. 